Research Article

\title{
Fire Behavior of Continuous Assembled Monolithic Hollow-Ribbed Slabs
}

\author{
B. Li $\mathbb{D}^{1}{ }^{1}$ X. Y. Ren ${ }^{D},{ }^{1}$ Y. Q. Lin, ${ }^{1}$ and L. L. Liu ${ }^{2}$ \\ ${ }^{1}$ College of Civil Engineering and Architecture, Hainan University, Haikou 570228, China \\ ${ }^{2}$ Shandong Provincial Key Laboratory of Appraisal and Retrofitting in Building Structures, Shandong Jianzhu University, \\ Jinan 250101, China
}

Correspondence should be addressed to B. Li; tingchao136@vip.163.com and X. Y. Ren; renxny@126.com

Received 18 November 2019; Revised 31 July 2020; Accepted 29 August 2020; Published 7 September 2020

Academic Editor: Melina Bosco

Copyright (C) $2020 \mathrm{~B}$. Li et al. This is an open access article distributed under the Creative Commons Attribution License, which permits unrestricted use, distribution, and reproduction in any medium, provided the original work is properly cited.

\begin{abstract}
To further understand the fire behavior of assembled monolithic hollow-ribbed (AMH) slab floor, a fire test was performed on six small-scale continuous AMH slabs (two by three). In this paper, the special designed furnace and relevant experimental phenomena are briefly introduced. Detailed experimental results in the form of furnace temperatures, temperature distributions, vertical deflections, and failure criteria are presented. The test data indicate that almost all the AMH slabs showed upward displacements during the fire tests, which is very distinct with the isolated AMH slab under fire. As the edge girders transformed into the frame girders gradually, the edge girders would show displacement plateaus. The integrity of the AMH slab under elevated temperature should receive more critical role to serve as its failure criterion compared with the load bearing function. Except fire environment, boundary constraint conditions also have a considerable effect on the elevated temperature deformations of the structural elements. At last, several rational suggestions are provided to improve the fire resistance of the AMH slabs.
\end{abstract}

\section{Introduction}

The AMH slab floor develops from the traditional ribbed floor and the cast-in-situ concrete hollow floor [1]. As a new type of floor slab, the characteristics of the AMH slab are not only light in weight and flexible structurally but also able to reduce floor height, save energy, and insulate sound. Therefore, the AMH slab is suitable for large-span buildings with relatively large loads. Figure 1 presents one type of the AMH slabs, and it consists of prefabricated congruent boxes and cast-in-place concrete ribbed girders and frame girders [2]. The prefabricated congruent boxes participate carrying the load with the ribbed girders and frame girders, as well as can be used as their side templates when casting concrete. The frame girders can be divided into frame hidden girders and edge girders as shown in Figure 2.

Now, the AMH slabs have been widely used in China and generate impressive social and economic values. This has motivated some scholars explore their mechanical behavior and design methods [3-5]. Ibrahim et al. [3] performed ninety linear and nonlinear analysis models to evaluate the response of various waffle slabs and found modified moment coefficients are needed for waffle slabs. Cheng et al. [4] put forward the analytical solutions for the deflection and bending moment of the cellular hollow plates and used finite element elastic analysis to testify the analytical solutions. The results showed that the above method can exactly calculate the deflection and bending moment of cellular hollow plates. Liu et al. [5] suggested the design method that can computer hollow floors as solid floors in PKPM software, and related tables were also presented as references for designers. Yang et al. [6] established a 3D finite element model of steel-concrete composite slim floors with the steel beam encased in concrete floor slabs and found monolithic composite slim floors possess high loading capacity for common buildings. Meanwhile, the other mechanical behaviors, such as seismic performance, shear resistance, and deformation capacity, were also being explored and have received some remarkable results [7-9]. The above existed literatures 


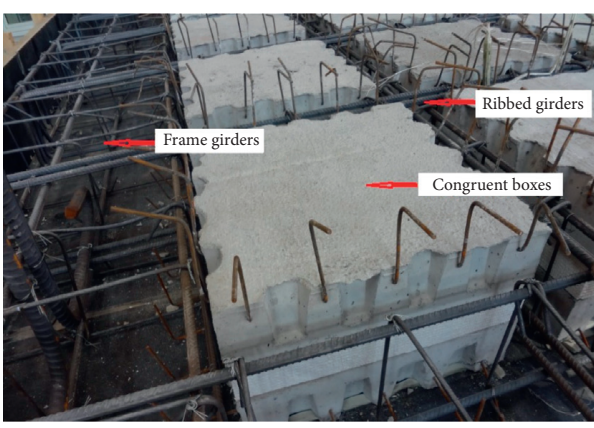

(a)

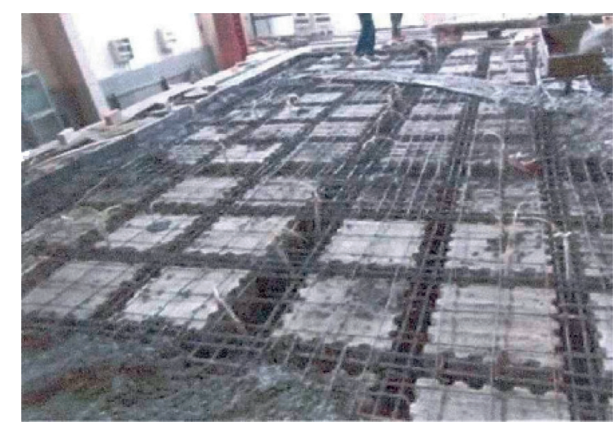

(b)

Figure 1: View of the continuous AMH slabs. (a) Structural skeleton; (b) concrete construction.

indicated that the AMH slabs have higher stiffness and stronger seismic performance compared with the conventional floor slabs. However, the real fire behavior of the $\mathrm{AMH}$ slabs is still unclear and has yet to be identified.

Fires as random events cannot be prevented, and the limited published documents have indicated the AMH slabs are sensitive to fire [10]. Thus, the study on the AMH slabs subjected to fire is urgent in developing suitable fire resistance design methods as well as to serve as a database for validation of numerical models. Before examining the fire behavior of the AMH slabs, it is worth reviewing those welldocumented fire tests of conventional reinforced concrete slabs. Wang and Dong [11] reported two fire tests of fullscale reinforced concrete slabs and found the failure pattern is different from those under normal temperature. Chen et al. [12] proposed a finite numerical model to analyze the behavior of the reinforced slabs exposed to fire. The results showed the predictions agree well with the experimental results. Moss et al. [13] carried out numerical modelling of the fire behavior of two-way reinforced concrete slabs, and the effects of the fires were discussed in relation to the redistribution of bending moments and the development of tension field action in the slabs. Li et al. [14-16] conducted three fire tests of two-way concrete slabs and showed that the complex interactions between members have great influence on their fire resistance. del Coz-Díaz et al. [17] conducted the standard fire tests of LWC and NC composite slabs with steel decking profile and found LWC composite slabs are very efficient in terms of energy saving and sustainability. When it comes to the AMH slabs under fire, Li et al. [2] tested two isolated AMH slabs under fire consisting of open boxes and covered boxes, respectively. However, the above two simplified fire tests neglected the complex interactions between members in real structures, thus the test results need to be further validated. In response to this need, a furnace test is conducted on the continuous AMH panels under the combined effects of constant loading and fire. In the meantime, the fire behavior of the continuous AMH slabs will be discussed and feasible actions of improving the performance of fire resistance are put forward. The present study intends to make a contribution to further understand the AMH slabs under fire.

\section{Description of the AMH Slab and Fire Test Furnace}

As shown in Figure 2, the test slabs located between the grid line A to $C$ and 1 to 4 with an area of $3 \times 2660 \mathrm{~mm}$ long and $2 \times 2040$ wide. Only three sides of the test slab installed jetted plates $(150 \mathrm{~mm}$ deep), which were designed to seal the furnace without load imposed, and the last side only installed edge girders. Obviously, the test slab itself is a part of the closed furnace.

The fire test was conducted on a specially designed fire test furnace at Shandong Jianzhu University, China, as shown in Figure 3. The test furnace has been designed in compliance with the requirements of industrial furnace and consists of a gas evacuation system, a smoke flue, a real time data acquisition system, and a observation system and restraint or support steel frames. It is designed to follow either a custom designed fire development profile or a timetemperature curve specified in fire resistance standards such as ISO-834 and ASTM-E119. The furnace can test vertical and horizontal elements such as floor, beam, wall, and slab elements and subject them to specific heating and load conditions. A plan view of the furnace, along with two sectional views (sections 1-1 and 2-2), has been shown in Figure 2. The underside of the test slab was heated by 14 oilfired burner nozzles which was located in the furnace walls symmetrically, and each nozzle was controlled independently from each other. The furnace walls at the perimeter of the furnace were constructed from firebricks and the mineral wool layer with a low thermal conductivity of $0.035 \mathrm{~W} /(\mathrm{m} \cdot \mathrm{k})$ at ambient temperature. The stainless steel plates were also installed at the four external sides to ensure the overall stability and fire insulation of the furnace. The gap between the top of the furnace walls and the test slab was filled with mineral wool to keep the test components deforming freely and to reduce heat loss. Four types $\mathrm{N}$ thermocouples N1-N4 were installed (two in each side as shown in Figure 3) to measure the temperatures of the gas inside the furnace. The construction of the furnace is similar to that in [12].

As shown in Figure 4, each congruent box has a plane size of $500 \mathrm{~mm} \times 500 \mathrm{~mm}$ and consists of a soleplate, a top 


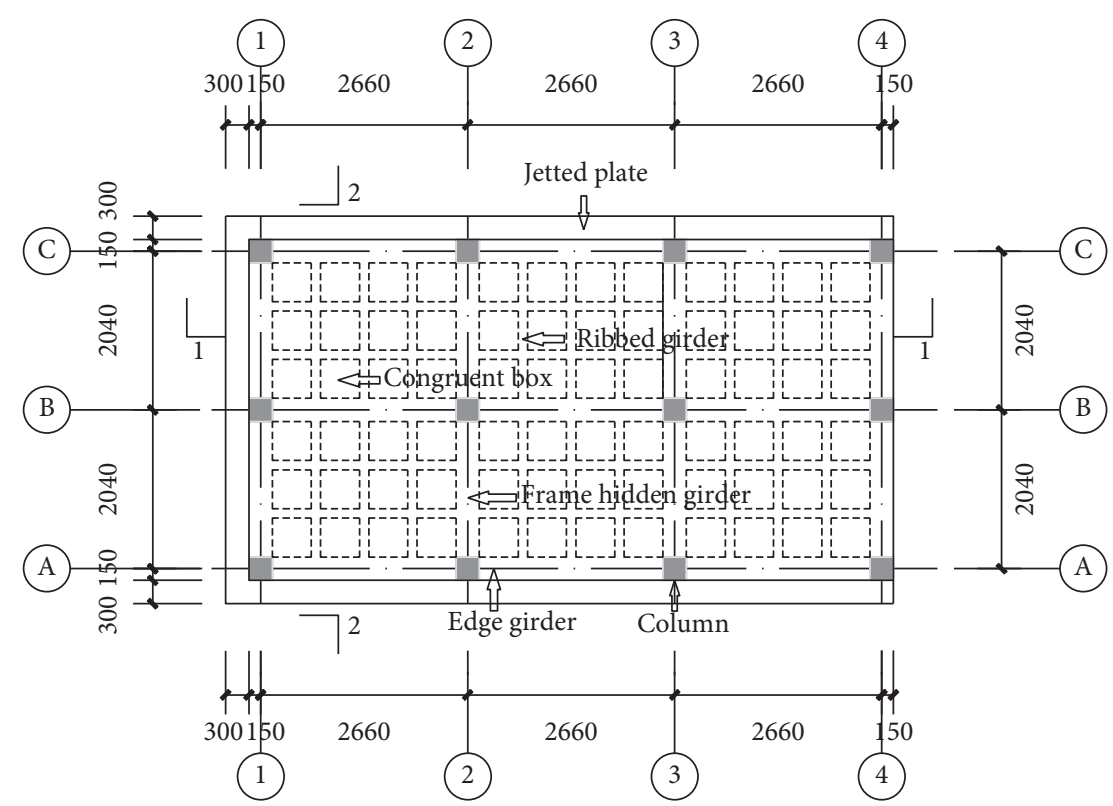

(a)

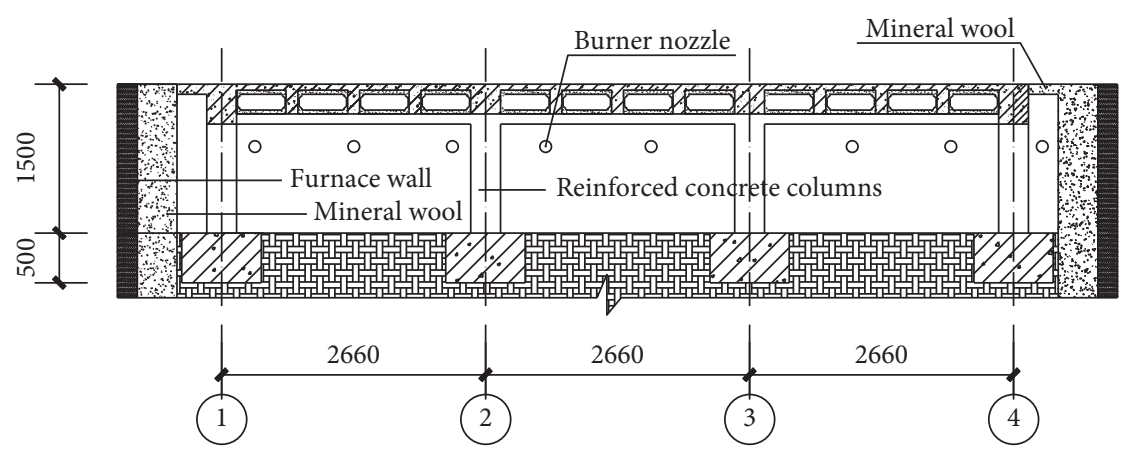

(b)

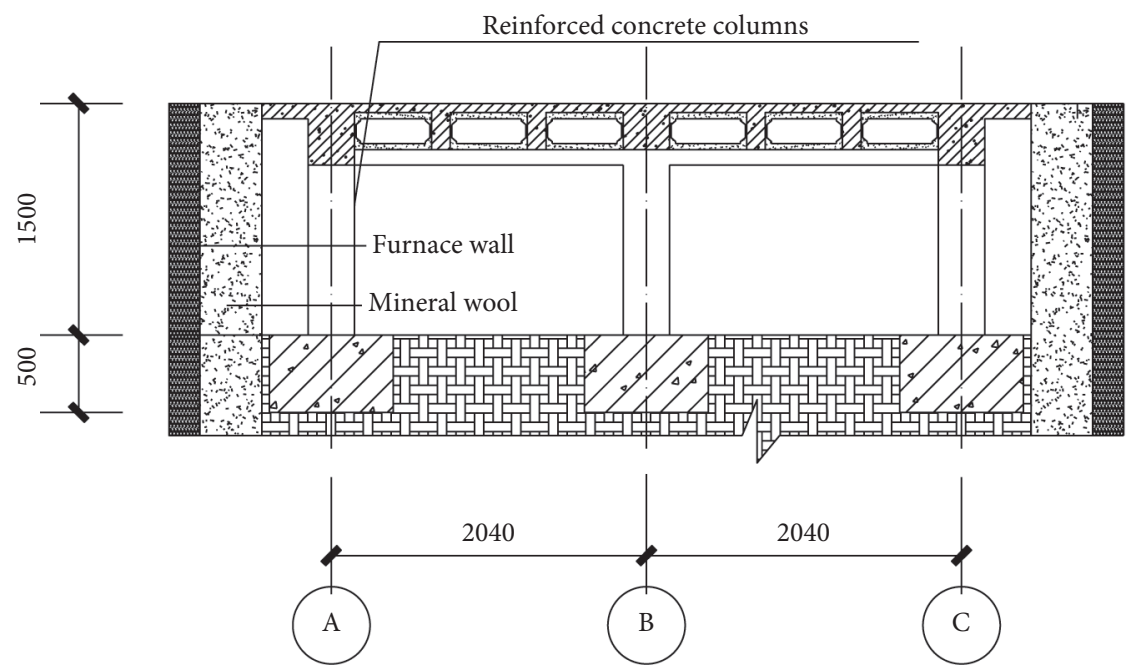

(c)

Figure 2: Plan view and front elevation view of the furnace. (a) Plan view of the continuous AMH slabs: (b) section 1-1; (c) section 2-2.

plate, and a rectangular frame plate. The soleplate and top plates are both $40 \mathrm{~mm}$ thick and reinforced by low carbon steel wires $(4 \mathrm{~mm}$ in diameter) which are arranged at a spacing of $150 \mathrm{~mm}$ along both directions. The rectangular frame plate is $40 \mathrm{~mm}$ thick without reinforcement and can be used as side templates when casting concrete. Furthermore, each congruent box has a section height of $240 \mathrm{~mm}$, while the section height of the test slab is $300 \mathrm{~mm}$ because 


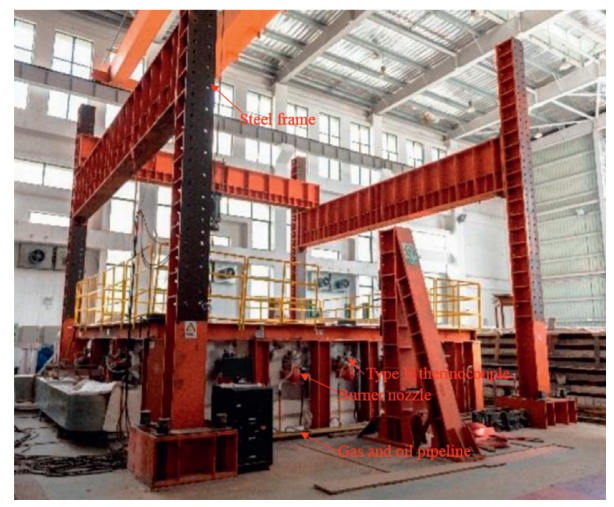

Figure 3: View of the furnace.

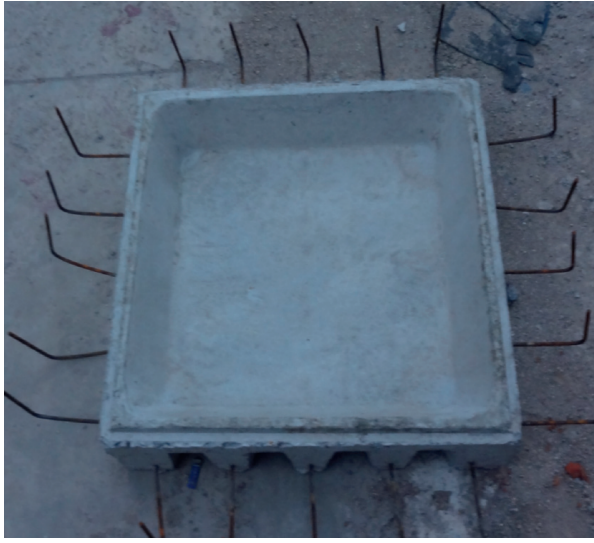

(a)

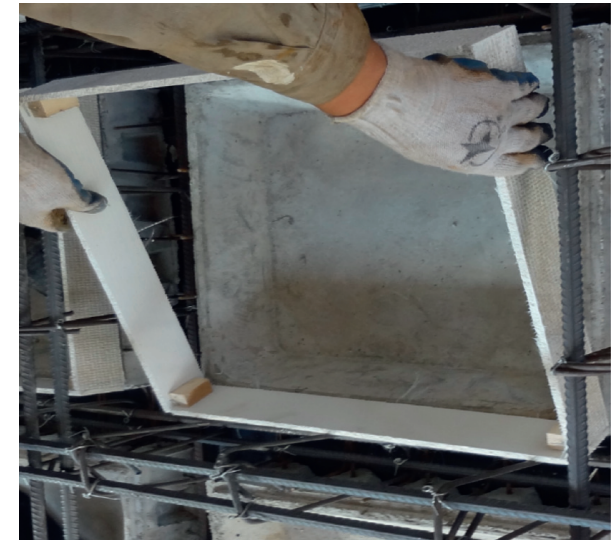

(b)

Figure 4: Congruent box. (a) Soleplate or top plate; (b) rectangular frame plate.

additional $60 \mathrm{~mm}$ thick cast-in-situ layer was installed at its upper surface. In addition, all the reinforced concrete columns have a section of $300 \mathrm{~mm} \times 300 \mathrm{~mm}$.

Figure 5 illustrates the detail constructions of ribbed girders, frame hidden girders, and edge girders within the AMH slabs. Their rectangular sections are $120 \mathrm{~mm} \times 300 \mathrm{~mm}$, $300 \mathrm{~mm} \times 300 \mathrm{~mm}$, and $300 \mathrm{~mm} \times 400 \mathrm{~mm}$, respectively. They are all reinforced with grade three hot-rolled reinforcing bars with a characteristic yield strength of $400 \mathrm{MPa}$. The actual yield and ultimate tensile strength are 426 and $573 \mathrm{MPa}$, respectively. The details of reinforcement arrangements are also annotated in Figure 5. In addition, the cast-in-situ layer at the top surface of the AMH slabs is reinforced with grade one hot-rolled reinforcing bars ( $8 \mathrm{~mm}$ in diameter) at a spacing of $200 \mathrm{~mm}$ along both directions. All congruent boxes are prefabricated by normal weight $\mathrm{C} 40$ concrete in factory, while the other cast-in-situ structural components are composed of normal weight C30 concrete. The average moisture content of the AMH slabs is $2.3 \%$ by weight measured ten days before the fire test.

\section{Test Program}

3.1. Loading Equipment. As shown in Figure 6, sand bags were placed on the upper surface of the AMH slabs to simulate the uniformly distributed load of $3.0 \mathrm{kN} / \mathrm{m}^{2}$ in addition to self-weight during the fire test [18]. The test slab was loaded at least two hours before the fire test. These sandbags were insulated from the test slab with wooden supports to avoid being damaged by high temperatures.

3.2. Temperature and Displacement Measurement. As shown in Figure 7, four N-type thermocouples N1-N4 were installed around the furnace walls to measure the gas temperatures; twelve thermocouple trees L1-L12 were used to record the temperature gradients along the cross-sections of the ribbed girders. In each thermocouple tree, thermocouples 1-5 were arranged to measure concrete temperatures of ribbed girders and the distance between them was approximately $65 \mathrm{~mm}$; likewise, thermocouples 6-7 were used to record the reinforcing steel temperatures, as shown in Figure 8. Four thermocouple trees named K1-K4 were arranged evenly to measure the temperatures of frame hidden girders, while thermocouple trees B1 and B2 were used to record the temperatures of edge girders. They received similar layouts of thermocouples as thermocouple trees L1-L12. Twelve types of $\mathrm{K}$ thermocouple trees M1-M10 were used to measure the temperatures of congruent boxes. And, in each thermocouple tree, two 


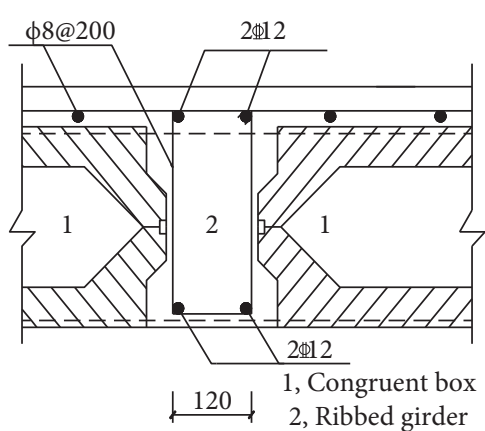

(a)

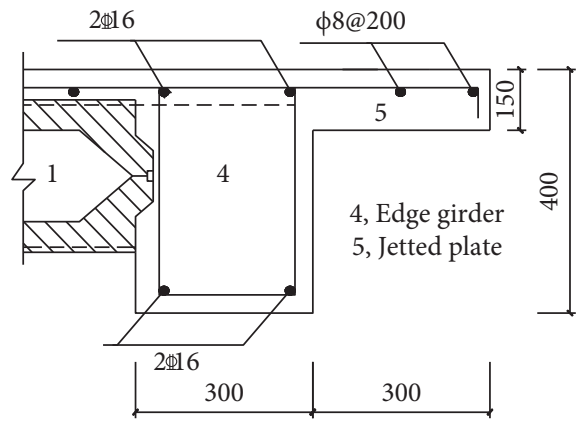

(c)

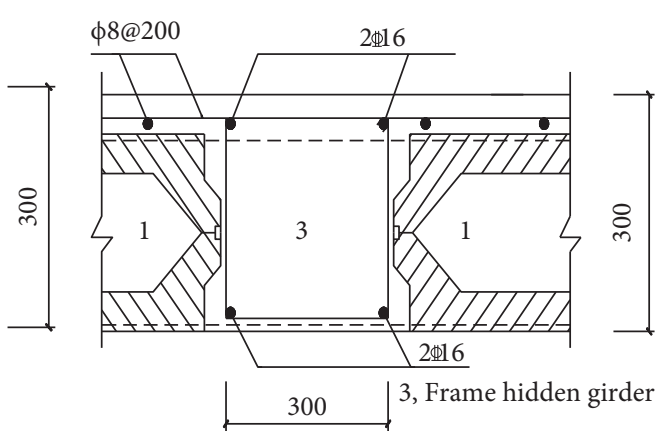

(b)

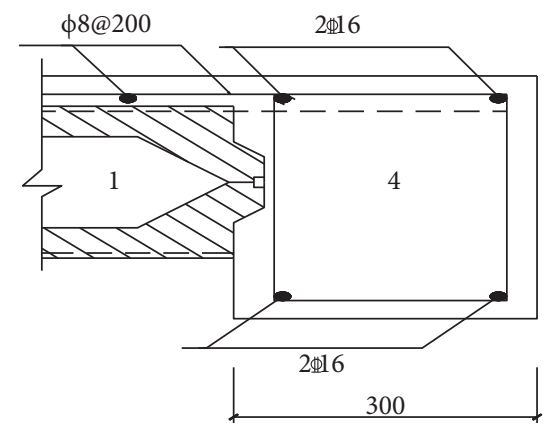

(d)

Figure 5: Sketch map of the AMH slabs. (a) Ribbed girder; (b) frame hidden girder; (c) edge girder with jetted plate; (d) edge girder without jetted plate.

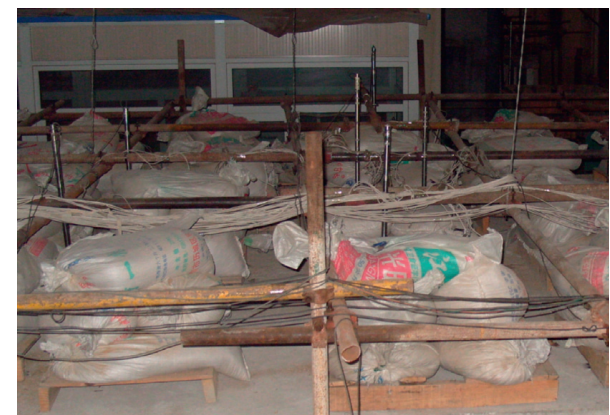

FIGURE 6: View of the loading.

thermocouples 8 and 10 were settled to record the temperatures of the soleplates and the top plates, respectively. At the same time, six type K thermocouples named G1-G6, corresponding to the thermocouple 9 as shown in Figure 8, were embedded to measure the air temperatures within congruent boxes. Thermocouple trees $\mathrm{Z} 1$ and $\mathrm{Z} 2$ were used to record the temperatures of beam-columns connections, and in each thermocouple tree, four thermocouples were arranged to measure concrete temperatures and the distance between them was approximately $130 \mathrm{~mm}$.

As shown in Figure 9, 26 linear voltage displacement transducers (LVDTs) were installed on the top surface of the test slab to measure its vertical displacements. The vertical displacements were measured across the center of the slab in the long and short directions. In this paper, the vertical upward displacements are positive and downward displacements are negative. Regretfully, its horizontal displacements were not involved. To easily report the experimental results, the six continuous slabs are labelled as panels A-F in order.

\section{Test Results and Discussion}

4.1. Testing Phenomenon. Some testing phenomenon observed during the fire test was recorded as shown in Figure 10. At $13 \mathrm{~min}$ after ignition, the test slab began popping noise due to crack propagation of the soleplates. At $24 \mathrm{~min}$, the fire has burned through some soleplates and entered the interior of the congruent boxes; meanwhile, the test slab fluctuated obviously. At $36 \mathrm{~min}$, some water marks occurred at the upper surface of the test slab due to evaporation of moisture and water migration. At $44 \mathrm{~min}$, most soleplates had been burned through and fell off seriously. At $69 \mathrm{~min}$, various hairline cracks began to appear at the top surface of the test slab; accordingly, lots of water vapor escaped from the cracks. At $119 \mathrm{~min}$, an increasing number of longitudinal cracks parallel to the frame hidden girders appeared. At $268 \mathrm{~min}$, the furnace was switched off in account of testing safety, although the test slab was not burned through significantly. Unfortunately, the crack spread during the cooling phase was not supervised. Therefore, some information of cracks was missing.

After the fire test, partial tiny cracks inevitably closed, but the main concrete spalling at the bottom surface of the test slabs were retained as shown in Figure 11.

Obviously, most of soleplates of congruent boxes turned white and fell off seriously, and only a few of soleplates were not burned through, but the frame plates showed almost no 


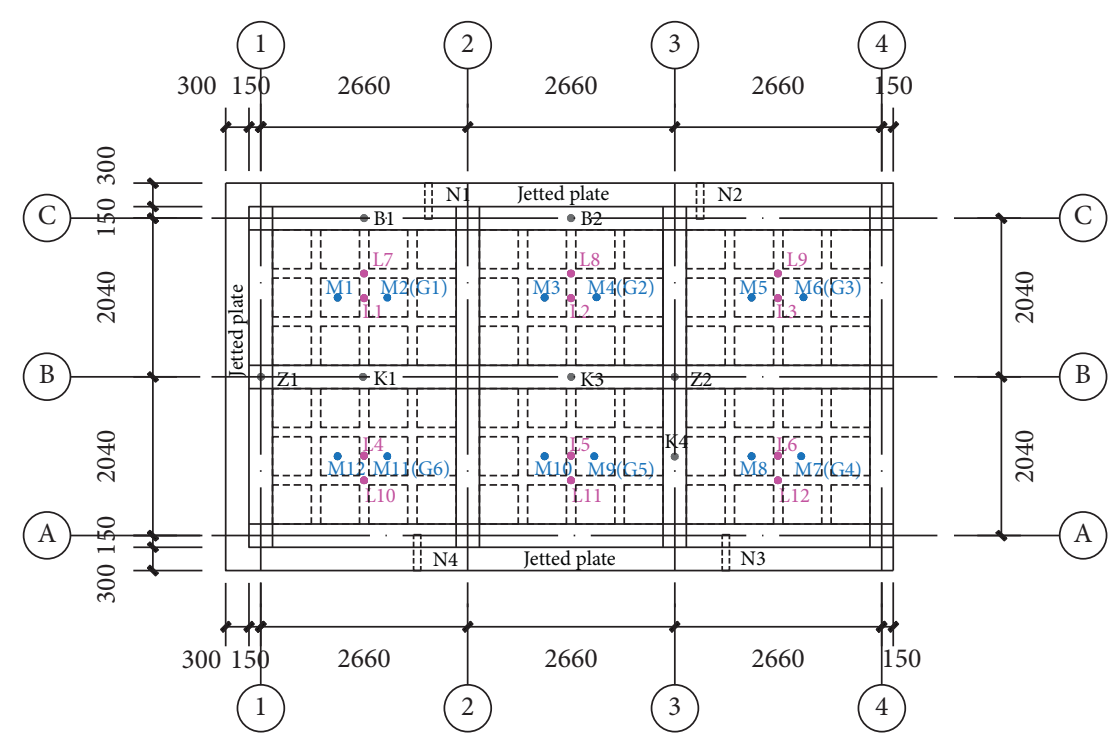

Figure 7: Furnace thermocouples and thermocouple trees in the AMH slabs.

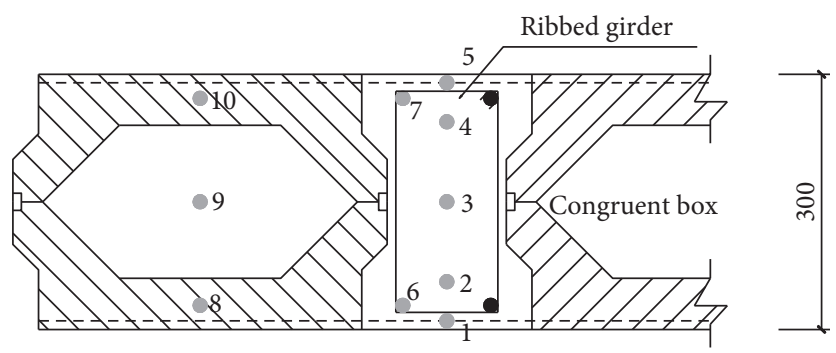

- Thermocouple

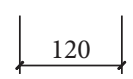

FIgURE 8: Arrangement of thermocouples.

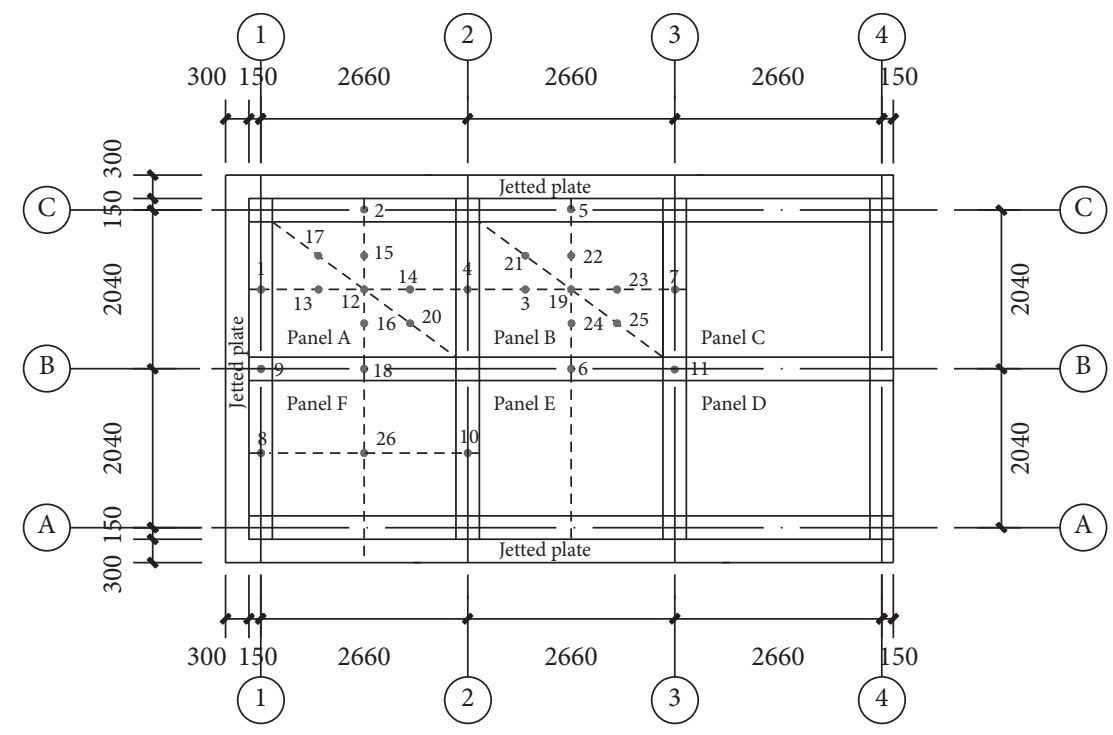

Figure 9: Displacement measure points at the top surface of the AMH slabs.

damage, which protected two sides of the ribbed girders and frame hidden girders against fire effectively. Thus, it seemed that they only subjected to fire directly at the bottom surfaces. In addition, the edge girders suffered more serious damage due to less protection compared with the ribbed girders and frame hidden girders. But, the above girders still 


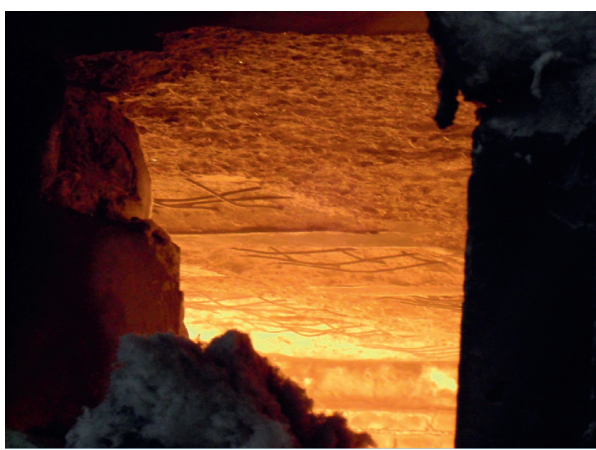

(a)

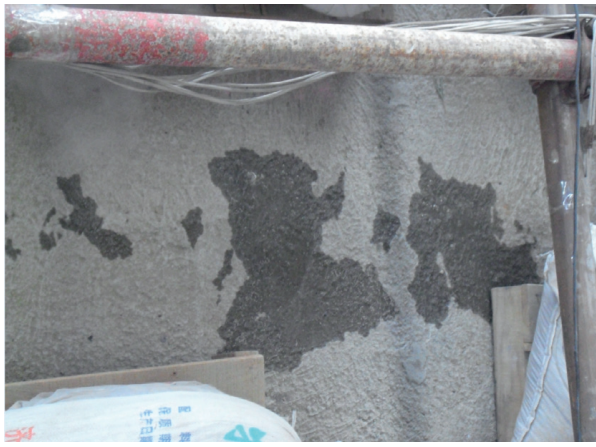

(c)

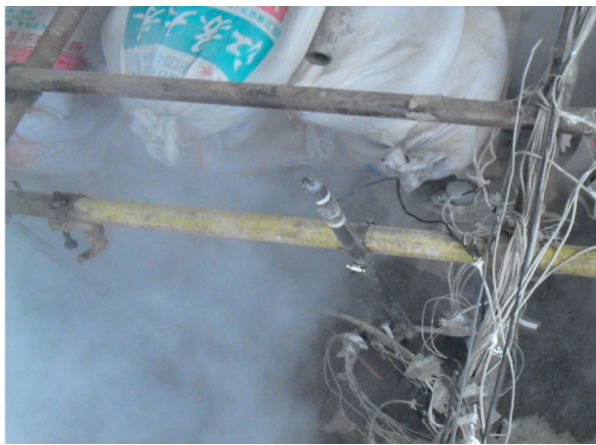

(e)

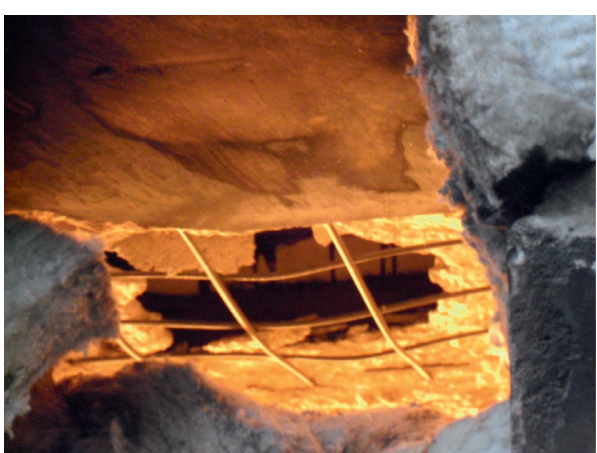

(b)

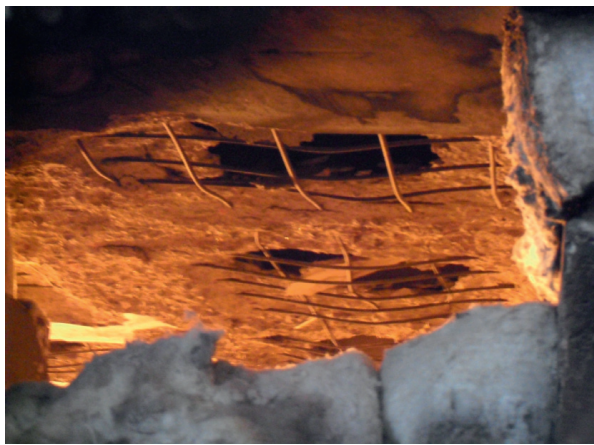

(d)

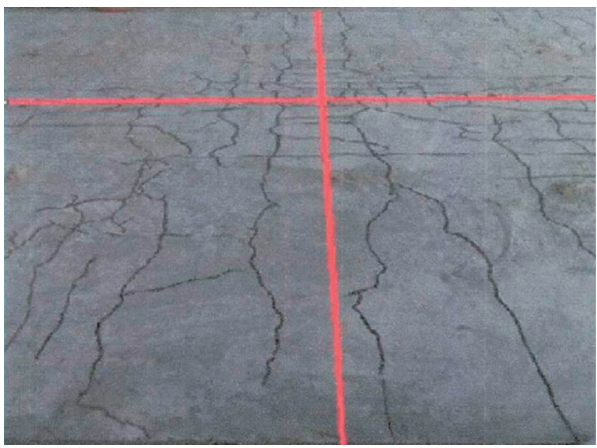

(f)

FIgURE 10: Photograph of the test slabs during the fire test at (a) 13 minutes, (b) 24 minutes, (c) 36 minutes, (d) 44 minutes, (e) 69 minutes, and (f) 119 minutes.

showed better fire resistance compared to the conventional concrete reinforced beams [19]. In order to keep stability of the test slabs, all columns plus their beam-column connections were protected by the aluminium-silicate refractory fiber blankets; thus, only at column ends occurred concrete spalling slightly.

4.2. Gas Temperatures. Four types of $\mathrm{K}$ thermocouples $\mathrm{N} 1-\mathrm{N} 4$ were used to monitor the furnace temperatures. As shown in Figure 12, the furnace temperature curves were similar to the standard ISO834 curve. During the fire test, the curves initiated a sharp rise and then continued to increase slowly until the furnace was shut off. The peak temperatures at $268 \mathrm{~min}$ after ignition were $1122,1007,1029$, and $1050^{\circ} \mathrm{C}$, with an average value of $1052^{\circ} \mathrm{C}$. After the furnace was shut off, the gas temperature dropped quickly until termination of the test at $520 \mathrm{~min}$ after ignition. Apparently, the furnace temperature distributed evenly within the furnace during the fire test.

4.3. Temperatures of Ribbed Girders. During the fire test, Type $\mathrm{K}$ thermocouples were used to measure the concrete and reinforcing steel temperatures. Two thermocouple trees L2 and L7, as shown in Figure 7, were chosen to analysis the temperature distributions of ribbed girders because all measure points received similar temperature curves during the fire test. Figure 8 shows the details of the layout of the thermocouple trees L2 and L7. Figure 13 shows the temperatures of thermocouple trees L2 and L7 in the ribbed girders. The peak temperatures at bottom of ribbed girders were $730^{\circ} \mathrm{C}$ and $874^{\circ} \mathrm{C}$, respectively, due to different levels of concrete spalling. The temperatures at the upper parts were 


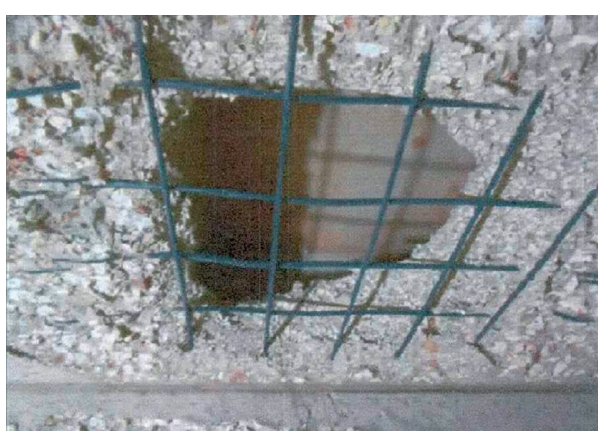

(a)

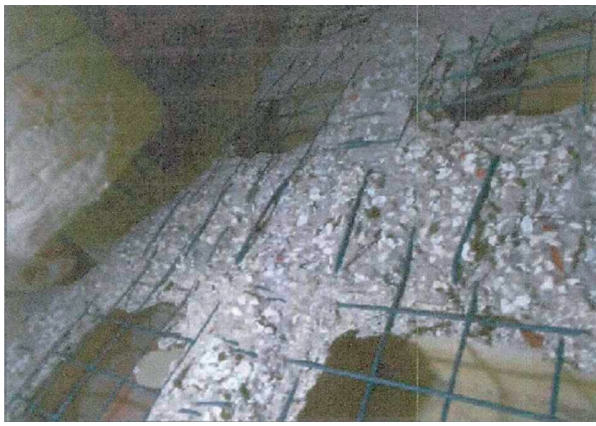

(c)

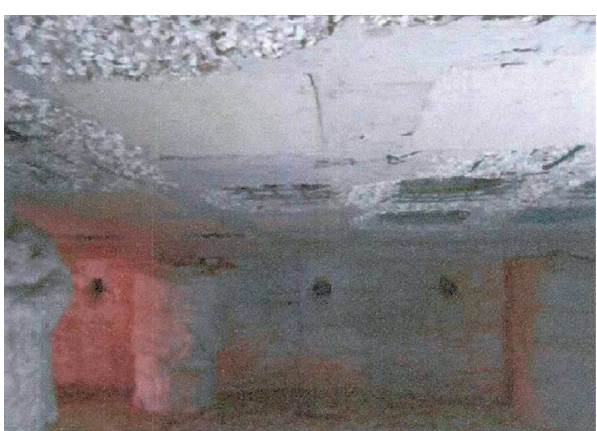

(b)

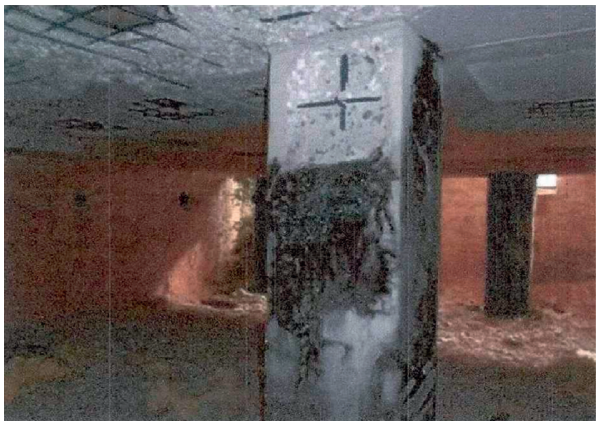

(d)

FIGURE 11: Concrete spalling at the bottom surface of the AMH slabs. (a) Burn through of soleplates, (b) without burn through of soleplates, (c) ribbed or frame hidden girders, and (d) column ends.

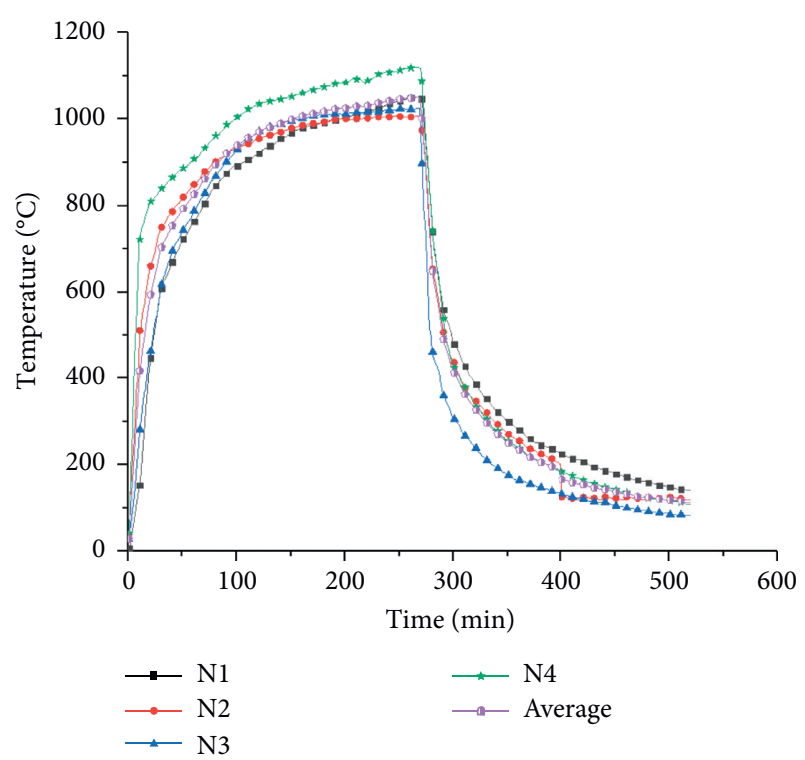

FIgURE 12: Recorded temperature-time relationships.

much lower than those at bottom surfaces compared with the conventional reinforced concrete beams subjected to fire, because the frame plates of the congruent boxes can protect the ribbed girders effectively; in other words, it seemed that only the bottom surfaces were exposed to fire. Thus, the ribbed girders in the test slab could form a reliable framework, which maintained the load bearing function during the fire test. The temperature curves of thermocouples $2-4$ at the central part of the ribbed girders initiated a slow rise and then continued to increase sharply as the fire developed until the furnace was shut off. This was due to that the ribbed girders were changed gradually from single surface subjected to fire to three surfaces subjected to fire [2]. Figure 13 also shows the temperatures of the top and bottom reinforcing bars during the fire test. The maximum temperatures of top reinforcing bars at L2 and L7 measure points were $175^{\circ} \mathrm{C}$ and $161^{\circ} \mathrm{C}$, respectively. Thus, the top reinforcing bars remained low temperatures without significant strength loss. However, the maximum temperatures of bottom reinforcing bars reached $643^{\circ} \mathrm{Cand} 693^{\circ} \mathrm{C}$, respectively. Thus, their yield strength dropped markedly due to their elevated temperature [20]. Figure 13(a) also shows that the temperatures of bottom reinforcing bars continued to increase dramatically after the shut off time, because heat conduction from the heated air within the congruent box to the ribbed girders held on, while Figure 13(b) never occurred above the phenomenon because the soleplates around the test ribbed girder were burned through and fell off; correspondingly, the temperatures recorded by L7 were relatively higher.

The temperatures at upper parts of the ribbed girders showed a clear plateau during the temperature rise phase at about $100^{\circ} \mathrm{C}$ level due to water evaporation. Additionally, after the furnace was shut off, the temperatures at upper parts continued to increase because heat conduction from the heated side to the unheated side held on as a result of temperature differentials. The above phenomenon also occurred during the heating of conventional reinforced concrete beams [21]. 


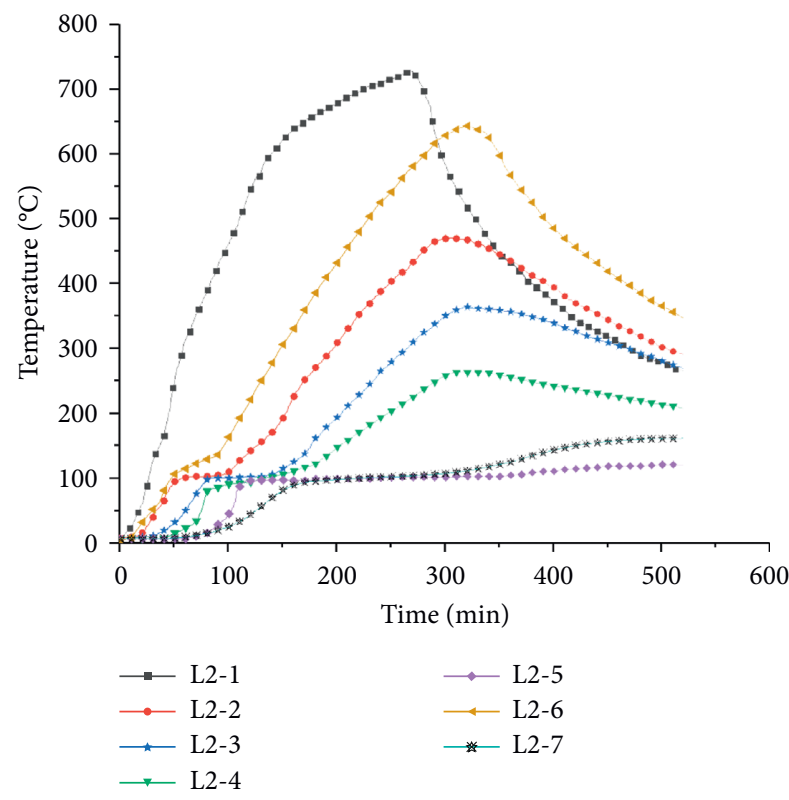

(a)

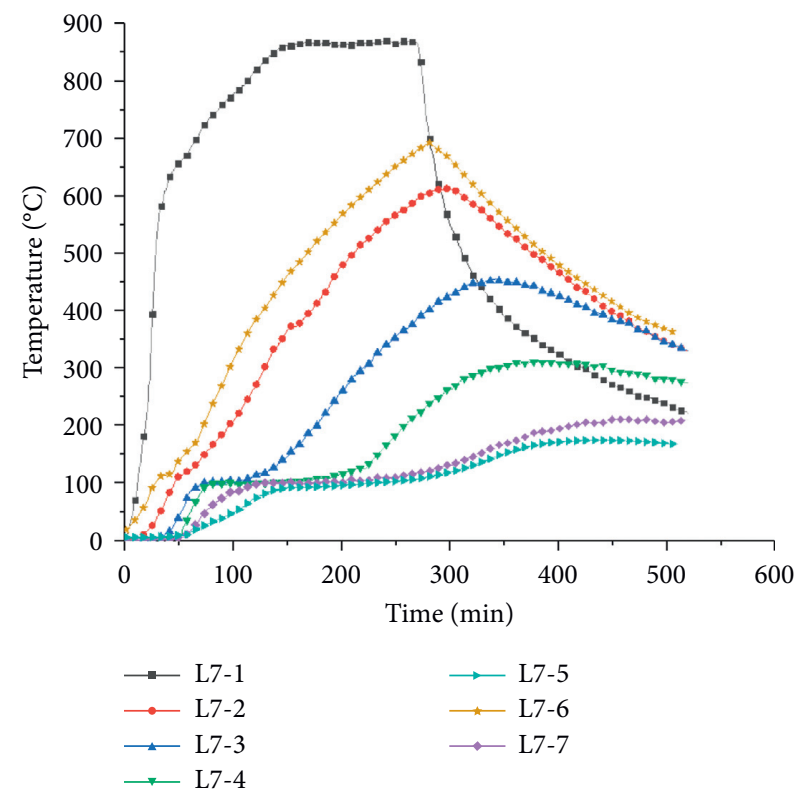

(b)

FIgURE 13: Temperature-time relationships of ribbed girders. (a) L2 measure point; (b) L7 measure point.

4.4. Temperatures of Frame Hidden Girders and Edge Girders. As shown in Figure 14, thermocouple trees K2 and B2 were chosen to discuss the temperature distributions of frame hidden girders and edge girders, respectively, because relevant temperature measure points recorded similar temperatures. Five thermocouples were embedded every $75 \mathrm{~mm}$ along the depth of frame hidden girders to only record the temperatures of concrete measure points; the maximum temperature at the bottom surface was $743^{\circ} \mathrm{C}$ at the shut off time. Obviously, the frame hidden girders received similar temperature distributions compared with the ribbed girders around which the soleplates were not burned through. While in edge girders, five thermocouples were attached every $100 \mathrm{~mm}$ distance along the section height to record the temperatures of concrete measure points and the maximum temperature at the bottom surface was $797^{\circ} \mathrm{C}$, which was relatively high compared with that in frame hidden girders, because both the bottom surface and partial side surface were subjected to fire directly. Due to concrete spalling at the bottoms of frame hidden girders and edge girders, the maximum temperatures of bottom reinforcing bars reached $613^{\circ} \mathrm{C}$ and $692^{\circ} \mathrm{C}$, respectively. But, the top bars remained low without significant strength loss.

4.5. Temperatures of Congruent Boxes. As mentioned above, most soleplates of congruent boxes began to generate concrete spalling and were burned through quickly at the early stage of the fire test. During the fire test, most soleplates were burned through and fell off seriously. Figure 15(a) shows the temperatures recorded by thermocouples M2 and G1 within congruent boxes, and their soleplate were burned through during the fire test. Apparently, temperatures of air within the congruent boxes and the soleplates were basically the same and obviously much higher than that of the top plates. The maximum temperature of air reached $888^{\circ} \mathrm{C}$, which led to serious concrete spalling of the top plates. Figure 15(b) shows the temperatures of the thermocouples M9 and G5 plotted as a function of time under the condition that the soleplates were not burned through. It could be found that the temperature gradients increased slowly at the initial stage and then quickly after $100 \mathrm{~min}$ of the fire test. The temperatures of the soleplates showed a clear plateau during the temperature rise phase at about $100^{\circ} \mathrm{C}$ level due to evaporation of water. After the furnace was shut off, the temperatures of the top plates of the congruent boxes continued to increase because heat conduction from the heated air within the congruent boxes to the top plates held on. Therefore, avoiding premature explosion of the soleplates of congruent boxes was crucial to improve the fire resistance of the AMH slab.

4.6. Temperatures of Slab-Column Connections. To maintain the stability of the test building, the slab-column connections were all protected from furnace heating by the aluminium-silicate refractory fiber blankets. Figure 16 shows the temperatures of the thermocouple tree $(\mathrm{Z} 2)$. Within $\mathrm{Z} 2$, four thermocouples numbered Z2-1 to Z2-4 were placed at $20,150,280$, and $430 \mathrm{~mm}$ intervals from the up surface of the test slabs to measure temperatures of the slab-column connection. The temperatures recorded continued to rise until 438 min after ignition due to heat conduction from the heated areas to the connections. Regretfully, the temperatures between $438 \mathrm{~min}$ and $520 \mathrm{~min}$ (shut off time) were not recorded because of equipment failure. The final temperatures recorded did not exceed $240^{\circ} \mathrm{C}$, thus the effect of temperatures on the reinforced concrete columns was not noticeable. 


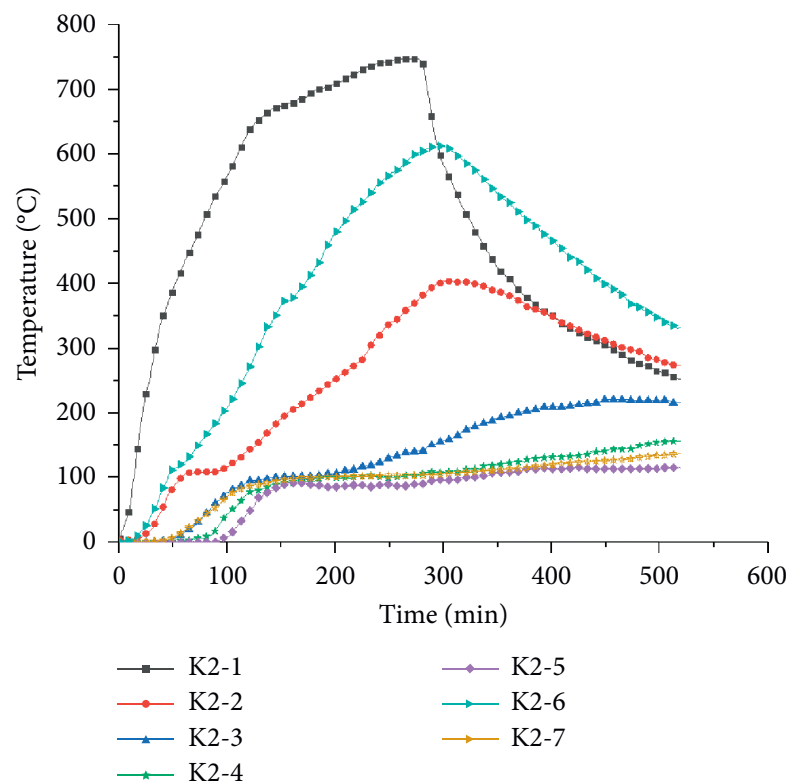

(a)

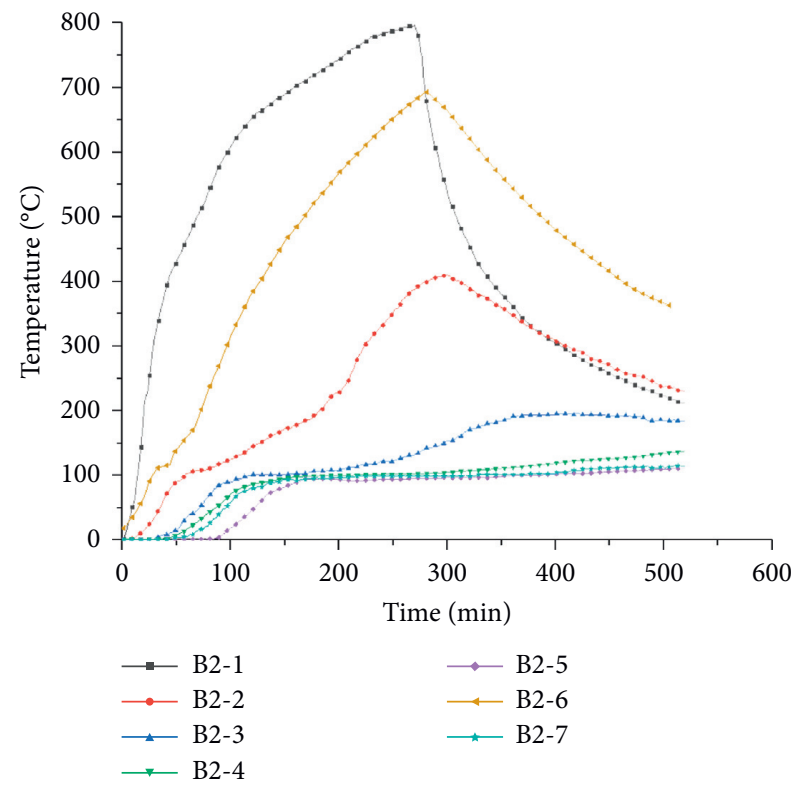

(b)

Figure 14: Temperature-time relationship of frame hidden girders and edge girders. (a) K2 measure point; (b) B2 measure point.

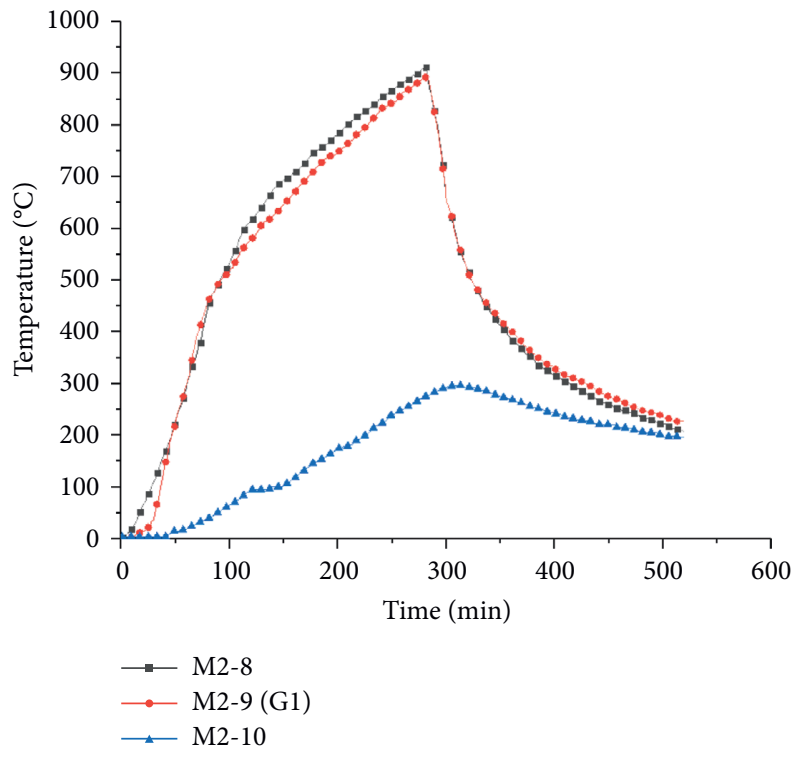

(a)

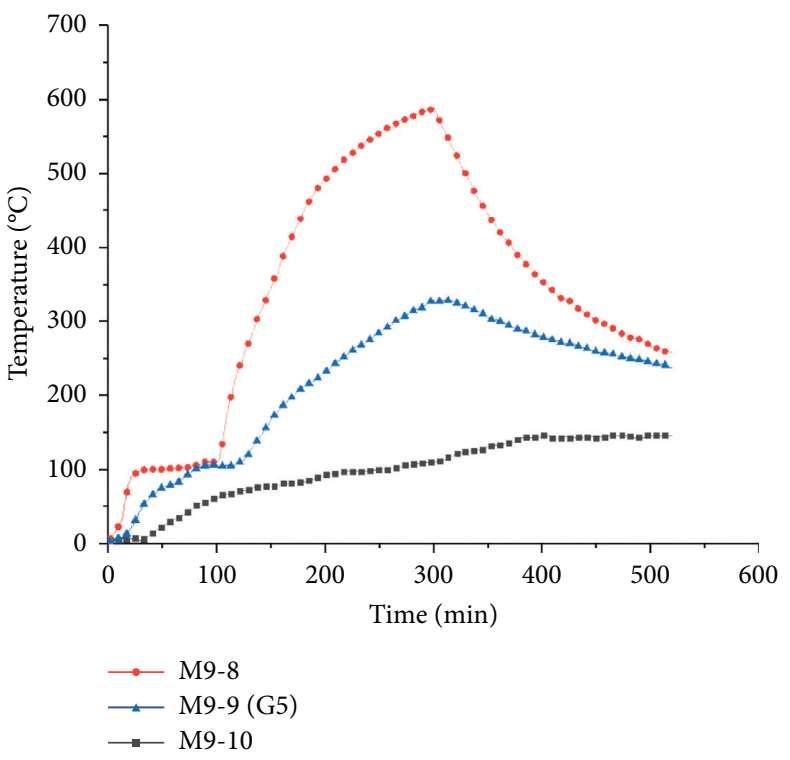

(b)

FiguRE 15: Temperature-time relationships of the congruent boxes. (a) M2 (G1); (b) M9 (G5).

4.7. Deflection Analysis. As discussed earlier, the displacements were measured by a set of LVDTs as shown in Figure 9. Figure 17 (a) shows the variation of the vertical displacements of panel A plotted against time during the heat-up and cool-down phases. Obviously, the deflections at the central point of panel A were upward because the thermally induced deformation (directed backwards the fire) is larger than the deflection due to load [22]. The maximum displacement recorded at the central point was $6.2 \mathrm{~mm}$, which corresponded to the maximum furnace temperature of $1050^{\circ} \mathrm{C}$ at the shut off time. It also indicated that the deflections of measurement points 15 and 16 at the upper surface of panel A were not symmetric due to the asymmetric boundary conditions. This phenomenon occurred due to the upward curvature and torsion of the heated edge girders, which provided additional displacements to point 15. Furthermore, the vertical displacements at points 14 and 16 were negative at the initial heating stage and changed gradually into positive displacements as the fire continued; the main reasons were as follows: firstly, $13 \mathrm{~min}$ after 


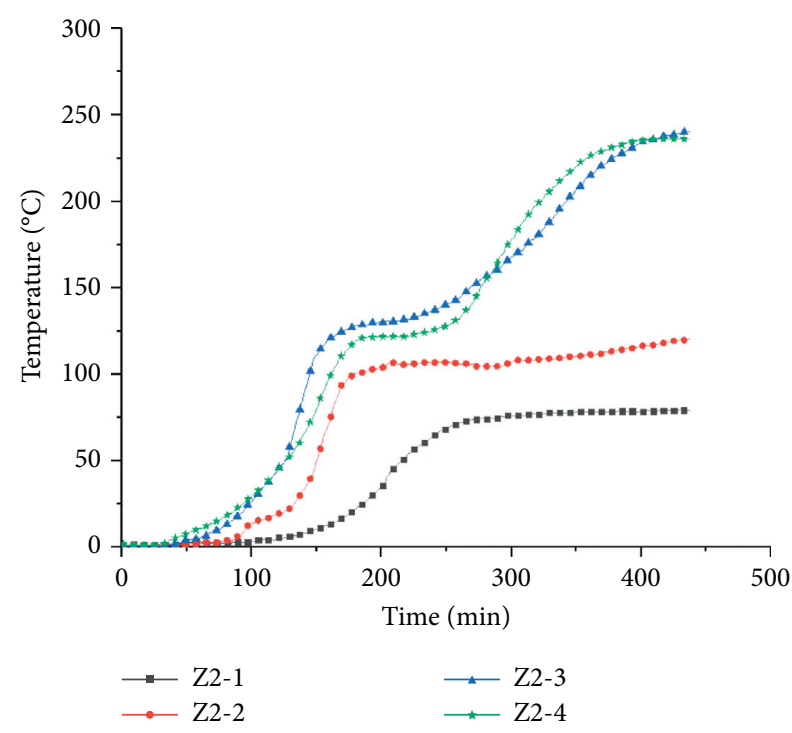

Figure 16: Temperature-time relationships of slab-column connections.

ignition, the soleplates began to show surface spalling and fell off quickly, which led to stiffness degradation of the panel A; thus, the downward deformation increased gradually; secondly, as the soleplates were burned through and exited the work, the structural system transformed into the ribbed floor system, which postponed the high temperature deformation. Meanwhile, the column strips turned gradually into frame hidden girders, which led to abrupt stiffness degradation, In fact, the above phenomenon is a complex interaction of the panel $A$ and adjacent frame hidden girders. After the furnace was shut off, the displacements gradually recovered. Obviously, the panel A showed strong displacement restoring capacity after cooling.

Figure 17(b) shows vertical displacements of panel B plotted as a function of time. The maximum upward displacement of panel B recorded by measure point 19 at its central point was $7.2 \mathrm{~mm}$, and it was larger than the maximum displacement of panel A due to stronger constraints around the panel B. After the furnace was shut off, the displacements began to recover slowly and fluctuation remained and the final residual deflection was $4.8 \mathrm{~mm}$. The displacements at measure points 3 and 23 were approximately equal due to similar boundary conditions. The displacements were all negative during the first 140 min of fire due to serious concrete spalling at the soleplates of congruent boxes and growing longitudinal cracks parallel to frame hidden girders, after which the displacements reversed and continued to increase until the test was terminated due to the remaining big flexural stiffness and constrained thermally induced deformation (upward). The displacements at points 22 and 24 always showed positive displacements; this was due to the upward displacements of the adjacent heated edge girders and frame hidden girders.

Figure 17(c) shows the midspan displacement changes of frame hidden girders. Obviously, they had similar deflection stages during the fire test. The maximum positive displacements at measure points 6 and 18 exceeded that at the measure points 4 and 7 because of greater boundary restraints. At neighboring measure points 4 and 7, premature concrete spalling at the soleplates of congruent boxes occurred, which alleviated the constrained thermal expansion effectively, thus almost all negative displacements were observed at measure points 4 and 7 . During the fire test, an increasing number of longitudinal cracks parallel to the frame hidden girders appeared and developed quickly; accordingly, frame hidden girders (columns strips) have become the frame beams; thus, the upward displacements at all measure points of the frame hidden girders increased slowly due to reduction of overall stiffness. After the shut off time, the displacements at measure points 6 and 18 maintained fluctuation due to complex stress redistributions within the AMH slabs.

Figure 17(d) shows the midspan displacements plotted as a function of time of edge girders. Obviously, the edge girders had similar deflection stages during the fire test. In the initial heating stage, a clear plateau occurred in the displacements at the measurement points 1,2, and 5; the main reasons were as follows: firstly, as the fire continued, the mechanical properties of the edge girders deteriorated gradually; additionally, the soleplates of the congruent boxes showed surface spalling and fell off quickly, which further led to stiffness degradation, and thus the vertical deformation increased gradually; secondly, as the soleplates of the congruent boxes were burned through and exited the work, the edge girders transformed into the frame girders, which postponed the high-temperature deformation. While the displacements at the measurement point 8 never exhibited plateau phenomenon, because some soleplates of the congruent boxes around the edge girder were not burned through and kept working. Thus, the integrity of the edge girder was kept, and the stiffness degradation was relatively low.

The supporting columns and adjacent beam-column connections were protected during the fire test. Thus, the columns within the furnace remained relatively cool, and their deflections recorded at measurement points 9 and 11 were always near zero. Therefore, the response of the protected columns during the fire test resembled those in ambient temperature due to the nearly identical material strength and stiffness.

This study exhibits a completely different response of the AMH slab compared with that of the conventional concrete slabs [23]. During the fire test, the vertical displacements of the AMH slab were obviously small compared with that of the conventional reinforced slabs with similar plane sizes; this may imply that the failure criterion of the AMH slab does not mainly depend on the load-bearing function.

\section{Fire Resistance Analysis and Discussion}

The fire test indicated the AMH slab has better fire behavior compared with conventional concrete slabs even though they are prone to occurrence of cracking and even spalling at the soleplates of congruent boxes during the fire test. As a new structure, the AMH slabs have no rational failure criterion under fire yet; the fire failure criterion of 


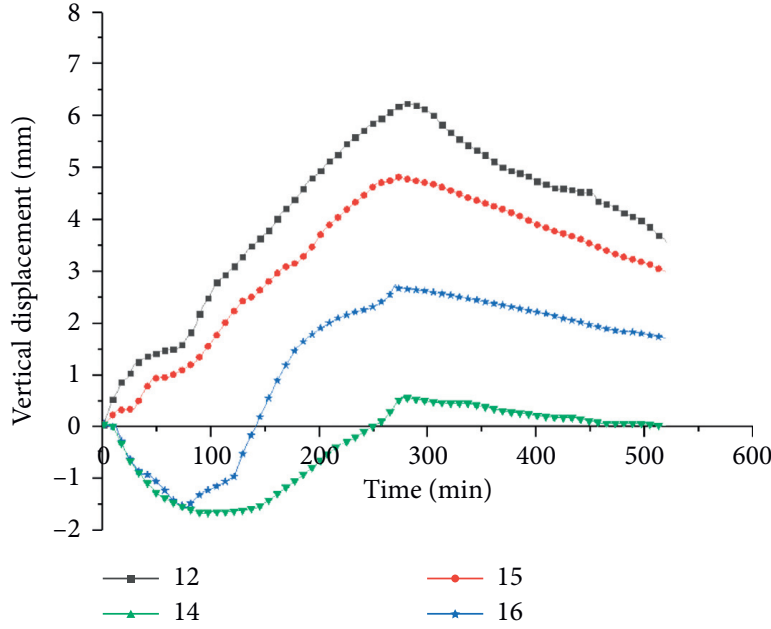

(a)

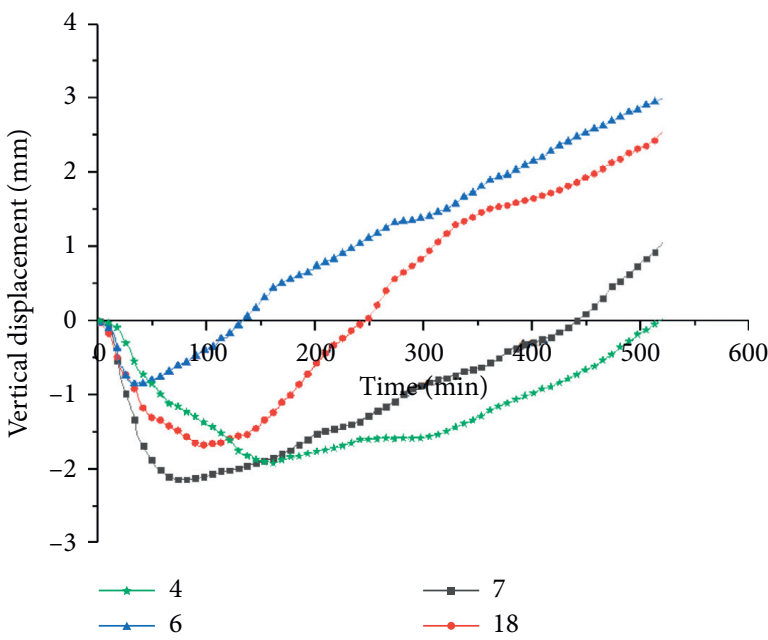

(c)

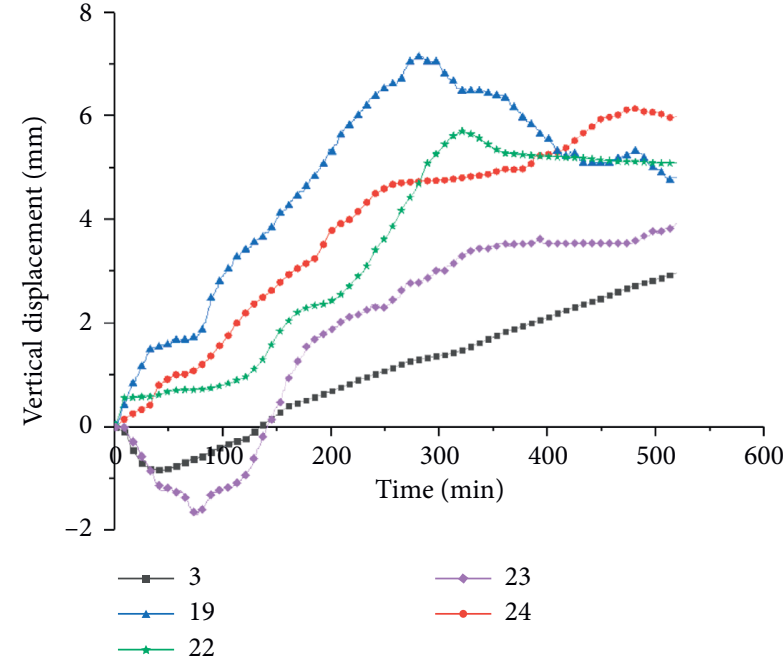

(b)

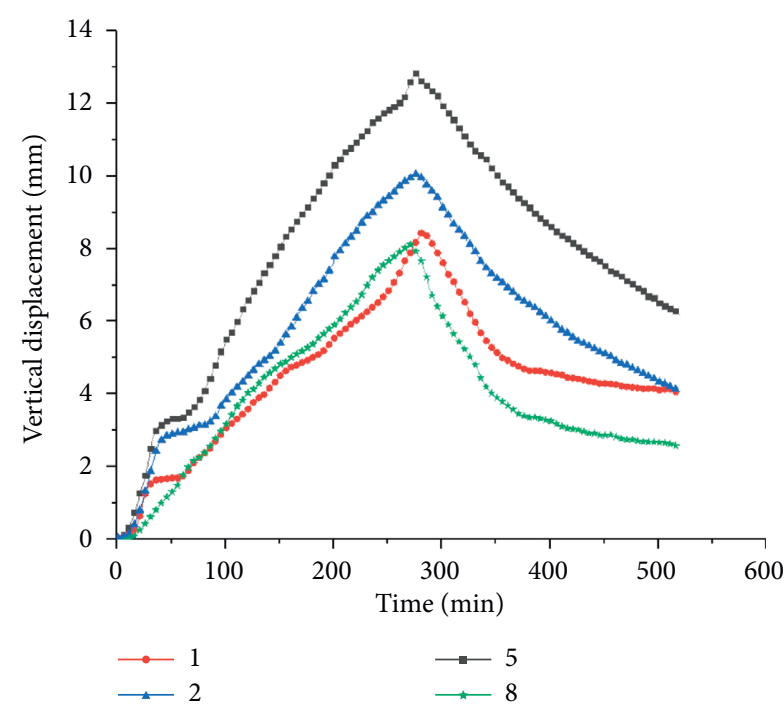

(d)

Figure 17: Vertical deflections-time relationship of the AMH slabs. (a) Panel A; (b) panel B; (c) frame hidden girders; (d) edge girders.

conventional reinforced slabs has to be adopted to discuss their fire resistance. Obviously, the load bearing function of the $\mathrm{AMH}$ slabs was maintained during the fire exposure time; and almost all the displacements of panels $\mathrm{A}$ and $\mathrm{B}$ were upwards, which are in opposite directions compared with those of the isolated AMH slab under fire, thus the inplane constraints have a considerable effect on the fire behavior of the AMH slab [24]. The test phenomenon indicated most soleplates of congruent boxes have been burned through since $40 \mathrm{~min}$ after ignition; as fire continued, the increasing number of cracks occurred at the top surfaces around panels A-F. Although the AMH slabs had never been burned through, its integrity under fire should receive more critical roles to serve as the failure criterion compared with that of the high temperature deformation. At 268 min after ignition, the average temperature rise over the whole of the nonexposed surface was $102^{\circ} \mathrm{C}$, and the maximum temperature rise was $125^{\circ} \mathrm{C}$. Thus, the insulation satisfied the specification requirements [23].

Although the fire resistance of the AMH slab meets the regulatory requirements, the service function is seriously affected due to most soleplates of congruent boxes that showed surface spalling and fell off. One of the main reasons was that some concrete mixed water entered the congruent boxes during construction. As the fire continued, the steam pressure in congruent boxes increased sharply; this further aggravated the surface spalling of soleplates of the congruent boxes and finally most soleplates were burned through at $40 \mathrm{~min}$ after ignition. In the meantime, some well-sealed covered boxes only exhibited surface spalling and were not burned through during the fire test. Therefore, the sealing quality of congruent boxes has a great influence on the fire resistance of the $\mathrm{AMH}$ slabs [2]. In view of indispensable concrete vibration, which is necessary to consolidate 
concrete and reduce the amount of air within the concrete, it is very difficult to keep the sealing capacity of congruent boxes under construction; thus improving the manufacturing technique of congruent boxes can be studied further. Regrettably, this small-scale test model may not fully represent the behavior of the $\mathrm{AMH}$ slabs in a real building due to the size effects [24]. Hence, further experimental and numerical studies are required to understand the fire behavior of the AMH slabs in the buildings and to establish a rational failure criterion. As an important innovation of the slab structure field, the AMH slabs combine many advantages of two traditional floor structure systems, and at the same time has solved many problems of traditional floor. In particular, the AMH slab has the characteristics of light weight, little material, good integrity, and spatial performance; thus, it can be used widely in large span, big space, or high load buildings.

\section{Conclusions}

A fire test was conducted on six small-scale continuous AMH slabs (two by three). Relevant test conclusions on gas temperatures, temperature distributions, vertical deflections, and failure modes were presented and discussed in detail. The test results were compared with those existing in the literature to understand the fire behavior of the $\mathrm{AMH}$ slab. Several general conclusions can be summarized as follows:

(1) During the fire test, the AMH slabs showed better fire resistance compared with conventional reinforced concrete slabs, but as a new type of floor system, the $\mathrm{AMH}$ slabs still need further optimum design to meet the requirements of fire resistance and service function.

(2) The AMH slabs almost all showed upward displacements during the fire tests due to strong boundary constraints.

(3) The integrity of the AMH slabs under fire should receive more critical roles to serve as the failure criterion compared with that of the high temperature deformation.

(4) As the edge girders transformed into the frame girders, the edge girders would exhibit displacement plateaus.

\section{Data Availability}

The research data used to support the findings of this study are available from the corresponding author upon request. At present, we are conducting finite element analysis of the assembled monolithic hollow-ribbed slabs under fire; thus, the data cannot be open now.

\section{Conflicts of Interest}

The authors declare that there are no conflicts of interest regarding the publication of this paper.

\section{Acknowledgments}

This research was supported by the NSFC (Grant no.: 51768017), Hainan Province Natural Science Fund (Grant no.: 20165189), and Lateral Science Foundation of Hainan University (Grant no.: HD-KYH-2020039). The authors gratefully appreciate the support.

\section{References}

[1] Z. Y. Qiu, Cast-In-Situ Hollow Concrete Floor, China Building Industry Press, Beijing, China, 2007.

[2] B. Li, Y. Q. Lin, H. L. Zhang, and M. J. Ma, "Fire behavior of the assembled monolithic hollow-ribbed slabs," Advances in Civil Engineering, vol. 2019, Article ID 8921502, 10 pages, 2019.

[3] A. Ibrahim, H. Salim, and H. S. El-Din, "Moment coefficients for design of waffle slabs with and without openings," Engineering Structures, vol. 33, no. 9, pp. 2644-2652, 2011.

[4] Y. B. Cheng, W. R. Cheng, and J. Dang, "Analytical solution of cellular hollow plates simply supported subjected to uniformly distributed loads," Engineering Mechanics, vol. 26, no. 8, pp. 35-38, 2009.

[5] L. X. Liu, H. T. Li, Q. B. Yu et al., "The analysis and design of the side supporting cast-in-situ hollow floor," Journal of Zhengzhou University (Engineering Science), vol. 28, no. 1, pp. 64-67, 2007.

[6] L. Yang, Y.-Q. Wang, and Y.-J. Shi, "FEA of the loading capacity of monolithic composite slim floors with deep decks," Journal of Chongqing Jianzhu University, vol. 30, no. 5, pp. 47-52, 2008.

[7] K. M. Mosalam and C. J. Naito, "Seismic evaluation of gravityload-designed column-grid system," Journal of Structural Engineering, vol. 128, no. 2, pp. 160-168, 2002.

[8] C. Q. Howard and C. H. Hansen, "Vibration analysis of waffle floors," Computers \& Structures, vol. 81, no. 1, pp. 15-26, 2003.

[9] S. do Socorro Melo de Souza, I. Abd El Malik Shehata, and L. da Conceição Domingues Shehata, "Shear resistance of reinforced concrete waffle flat slabs around the solid panel," Materials and Structures, vol. 49, no. 4, pp. 1367-1380, 2015.

[10] X. H. Zhou, W. Chen, and F. B. Wu, "Study on stiffness of assembled monolithic concrete hollow floor with two-way ribs," Journal of Building Structures, vol. 32, no. 9, pp. 75-83, 2011.

[11] B. Wang and Y. L. Dong, "Experimental research of four-edge simple supported two-way reinforced concrete slab under fire," Journal of Building Structures, vol. 30, no. 6, pp. 23-33, 2009.

[12] S. C. Chen, A. Z. Ren, J. F. Wang et al., "Numerical modeling of reinforced concrete slabs subjected to fire," Engineering Mechanics, vol. 25, no. 3, pp. 107-112, 2008.

[13] P. J. Moss, R. P. Dhakal, G. Wang, and A. H. Buchanan, "The fire behavior of multi-bay, two-way reinforced concrete slabs," Engineering Structures, vol. 30, no. 12, pp. 3566-3573, 2008.

[14] B. Li, Y.-L. Dong, and D.-S. Zhang, "Fire behaviour of continuous reinforced concrete slabs in a full-scale multistorey steel-framed building," Fire Safety Journal, vol. 71, pp. 226-237, 2015.

[15] Z. N. Yang, Y. L. Dong, and W. J. Xu, "Fire tests on two-way concrete slabs in a full-scale multi-storey steel-framed building," Fire Safety Journal, vol. 58, pp. 38-48, 2013.

[16] Y. Wang, Y.-L. Dong, B. Li, and G.-C. Zhou, "A fire test on continuous reinforced concrete slabs in a full-scale multi- 
story steel-framed building," Fire Safety Journal, vol. 61, pp. 232-242, 2013.

[17] J. J. del Coz-Díaz, J. E. Martínez-Martínez, M. AlonsoMartínez, and F. P. Álvarez Rabanal, "Comparative study of light weight and normal concrete composite slabs behaviour under fire conditions," Engineering Structures, vol. 207, Article ID 110196, 2020.

[18] China Building Industry Press, Load Code for the Design of Building Structures, China Building Industry Press, Beijing, China, 2012.

[19] M. M. El-Hawary, M. R. Ahmed, A. Abd El-Azim, and E. Shadia, "Effect of fire on flexural behavior of RC beams," Construction and Building Materials, vol. 10, no. 2, pp. 147150, 1996.

[20] Eurocode 3, Design of Steel Structures. Part 1.2: General RulesStructural Fire Design, Commission of the European Communities, Brussels, Belgium, 2003.

[21] V. K. R. Kodur and M. Dwaikat, "A numerical model for predicting the fire resistance of reinforced concrete beams," Cement and Concrete Composites, vol. 30, no. 5, pp. 431-443, 2008.

[22] E. Annerel, L. Lu, and L. Taerwe, "Punching shear tests on flat concrete slabs exposed to fire," Fire Safety Journal, vol. 57, pp. 83-95, 2013.

[23] China Standards Press, Fire-resistance Tests- Elements of Building Construction- Part 1: General Requirements, China Standards Press, Beijing, China, 2008.

[24] Y. Wang, G. Yuan, Z. Huang, J. Lyv, Z.-Q. Li, and T.-Y. Wang, "Experimental study on the fire behaviour of reinforced concrete slabs under combined uni-axial in-plane and out-ofplane loads," Engineering Structures, vol. 128, pp. 316-332, 2016. 